\title{
Isolation and Characterization of Secondary Metabolite from the Stem Bark Extract of Allophylus africanus Beauv (Sapindaceae)
}

\author{
C.G. Kwekowe ${ }^{1}$, E.O. Johnbull ${ }^{1}$ and I.E. Otuokere ${ }^{1^{*}}$ \\ ${ }^{1}$ Department of Chemistry, Michael Okpara University of Agriculture, Umudike \\ *Corresponding Author's Email: ifeanyiotuokere@gmail.com_+2347065297631 \\ Received 23 January 2021; accepted 13 March 2021, published online 8 April 2021
}

\begin{abstract}
Isolation of secondary metabolites from the stem bark of Allophylus africanus Beauv (Sapindaceae) was carried out. The plant has a wide distribution in West Africa, with Nigeria (Mambila Plateau, Calabar) inclusive. It has been used in communities for both its medicinal and economic importance. The stem bark of $A$. africanus was extracted by percolation using chloroform as solvent and concentrated by evaporation at room temperature. Single spot with an $\mathrm{Rf}$ value of 0.87 was obtained at a solvent mixture of hexane: chloroform at ratio 2:8 from finger column chromatography . Characterization using spectra analysis which include FT-IR, ${ }^{1} \mathrm{H}-\mathrm{NMR},{ }^{13} \mathrm{C}-\mathrm{NMR}, \mathrm{H}-\mathrm{H}$ COSY, H-C COSY, 135 DEPT and mass spectroscopy. Spectroscopic studies of A. Africanus stem bark extract led to the elucidation of the structure of the compound. FT-IR spectrum indicates that the compound is an aromatic derivative. Aromatic protons where seen at the ${ }^{1} \mathrm{H}-\mathrm{NMR}$ chemical shift values of $7.25 \mathrm{ppm}$. Olefinic protons at $5.124,5.146$ and $6.162 \mathrm{ppm}$ appeared as doublets of doublets of doublets. The compound 1-((E)7(((1E,5E)-6-((2,3-dimethyl-4-(((E)-3,4,5,6-tetramethyldeca-7,9-dien-2-yl)oxy)pentyl)oxy)-3,4dimethylhexa-1,5-dien-1-yl)oxy)hept-4-en-1-yl)-4-propylbenzene was isolated.

Keywords: Allophylus africanus, spectroscopy, isolation, characterization, aromatic, chromatography
\end{abstract}

\section{INTRODUCTION}

Allophylus africanus belongs to the Sapindaceae family, one of the most important forest species conserved and valued in Africa due to their multiple uses, high nutritional content, and medicinal values. It is commonly known as African false currant, akaito (in Igbo language, Nigeria), ebe/ukpe (esan tribe in Edo state, Nigeria), akanro, akaraesu (in Yoruba, language, Nigeria) and karki (in Hausa, language, Nigeria). It is a shrub with flowers that are small and creamy-yellow [1]. The fruit is fleshy and also red to black in colour when ripe [1]. A. africanus mostly grows in riverine areas, open wood land and forest edges, often associated with mounds, at an altitude of 960-1540 m. Its flowering time is usually December to March. It is distributed widely throughout tropical Africa, extending to the Eastern Cape South Africa [1]. A. africanus has been reported to be used as not just for medicinal purposes but, also as food and horticulture [1]. In ethno medicine, the leaves are used for the treatment of several ailments such as arthritis, rheumatism, gout, haemorrhoids, dysentery, venereal diseases and malnutrition [1], root and twig are used as chewing stick for dental and oral healthcare and diarrhoea treatment. A. africanus is reported to demonstrate biological activities such as antibacterial, anti-oxidant [2] and anti-malarial activity [3]. Some chemical components reported from A. africanus leaves are tannins, saponins, flavonoids and carbohydrates [3]. A. africanus is a shrub or small tree with trifoliate leaves, obovate leaflets, variously hairy, margin dentate, serrate or almost entire. Inflorescences axillary, often branched, spike-like. Flowers are creamy-yellow and small [1]. The fruit is near spherical, fleshy, red black when ripe [1].

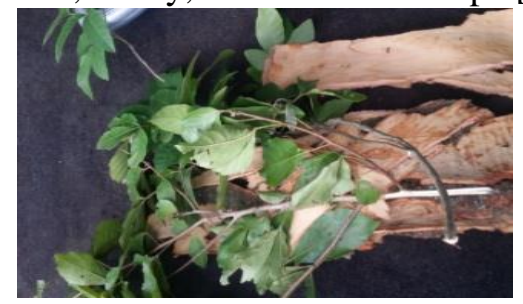

Figure 1: Allophylus africanus stem bark and leaves

The oil of seeds of Allophylus natalensis and Allophylus dregeanus were reported to both contain type I cyano-lipids, 1-cyano-2hydroxymethyl prop-2-en-1-ol diesters and also small amounts of type III cyanolipids, 1-cyano2-hydroxymethyl prop-1-en-3-ol diesters [4]. 
Allophylus serratus is reported to contain plant constituents like apigenin -4-0- $\beta-0$-glucoside, pinitol, quercetin, luteolin-7-o- $\beta-\mathrm{D}$ glucopyranoside, rutin [5], phenacetamide and $\beta$-sitosterol [6] . L-Quebrachitol was reported isolated from A. edulis [7].

Reported in preliminary chemical characterization of the aqueous extract of $A$. cominia leaves are protein concentration, fatty acids and carbohydrates [8]. Reported Gas Column-Mass Spectrophotometry (GC-MS) analysis of A. Serratus Kurz showed the plant to be rich in phenolics, flavonoids, tanning substances, saponins. Various fatty acids were also identified [9]. Predominance of tannins, saponins, flavonoids and carbohydrates in leaves and other parts of $A$. africanus have been reported [3]. It has been reported that 32 compounds representing $88 \%$ of the essential oil from leaves of $A$. africanus were characterized and 35 compounds from oil of flowers of $A$. africanus were identified [10]. In addition, isolation and identification of four new compounds, allotaraxerolide, alloeudesmenol, hanocokinoside and alloaminoacetaldehyde together with 2 compounds known, pinitol and stigmastane- $3 \beta, 4 \beta$-diol were reported in the whole plant of $A$. africanus [11].

Reported isolated compounds from whole plant of A. africanus are allotaraxerolide, hanocokinoside, alloeudesmenol,

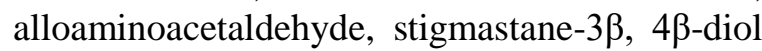
and pinitol. The essential oil from leaves of the plant was reported to be dominated by $2-(1$, 1dimethylethoxy)-ethanol, caryophyllene oxide, trimethylbenzene, 1-Ethyl- 21 1,4dimethylbenzene and hexahydrofarnesyl acetone [10] . Phytochemical studies reportedly revealed a predominance of carbohydrates, flavonoids, saponins and tannins [3].

Traditionally, the boiled bark, root and leaves are used in aches, fever and rheumatic pains and economically, the wood is a good source of building materials, and as insecticide. The ethanol extract of Allophylus serratus Kurz has been assayed for antiviral activity and was found to show antiviral activity against Ranikhet disease virus. It also showed gross effect on hypothermia and the central nervous system [9]. Antimalarial activity of $A$. africanus extract has been reported following suppression of parasitaemia in infected mice by $92.82 \%$ $97.81 \%$ on day 7 post infection against $96.81 \%$ for chloroquine [3].

Allophylus serratus has strong ethnobotanical and ethanopharmacological background. The plant has a distinction of being used in Indian system of medicine (Ayurveda) as an antiinflammatory, as carminative drug, treatment of elephantiasis, oedema, fractured bones, in bone dislocations, wound, ulcer, several gastrointestinal disorders such as dyspepsia, anorexia and diarrhea [12] . The fruits are sweet, edible and have cooling and nourishing tonic. The flesh of the berry is eaten raw to expel tapeworm. The leaves are crushed into juice and used to reduce fever, to relieve rashes, promote lactation, to treat colic [13, 14]. Grounded leaves with quicklime are applied with heat to relieve stomach aches. Leaves and barks are used as a remedy for elephantiasis; antiulcer and reduce piles $[13,14]$. Leaf paste with turmeric is applied for fracture and sprains [15]. The roots of this plant contain tannin and are considered astringent; they are used for treating piles and nose bleeding and to check diarrhea and rheumatic pains [13].

Allophylus serratus contains different bioactive substances which are very important as medicines and other activities. It is rich in phenolic compounds, flavonoids, tanning substances, Steroids, Alkaloids and Saponins [9]. Screened Pharmacognosy and phytochemistry of A. serratus (Kurz) have been reported [9]. The presence of various chemicals in different parts was observed [9]. The plant leaves contain $\beta$ - sitostrerol and phenacetamide, $\mathrm{Ph}$-acetamide, alkaloids and Benzylamide. Fruits contain three cyanogenic glycosides (3-0- -Dglucopyranosyloxy-4- methyl-2 (5H)-furanone, 4-0-D-glucopyranosyloxy-3-hydroxymethyl

butyronitrile-2-ene and cardiospermin [17]. There are also alkaloids and various fatty acids in leaves and $\beta$-sitosterol in stems $[9,17]$. There are reports which indicate that this plant also contains different compounds such as quercetin, pinitol, luteolin-7-O-d-glucopyranoside, rutin and apigenin- 4- O-D-glucoside [18]. Literature reports on isolation and characterization of bioactive compounds from the stem bark of $A$. Africanus is scanty. We hereby present isolation 
and characterization of secondary metabolite from chloroformed stem bark extract of $A$. africanus

\section{MATERIALS AND METHODS \\ Chemicals}

All the solvents and reagents used in this work were of analytical grade and were obtained from Merck Chemical Company. Infrared spectrum (KBr pellets) was recorded on a Perkin-Elmer 1605 FT-IR spectrophotometer. ${ }^{1} \mathrm{H}$ and ${ }^{13} \mathrm{C}$ NMR spectra were obtained on a Bruker AC400 (400 and $100 \mathrm{MHz}$ ) and $\mathrm{AC}-500$ (500 and $125 \mathrm{MHz}$ ) spectrometer using $\mathrm{CDCl}_{3}$ as solvent and TMS as the internal standard. Mass spectrum was recorded on Shimadzu QP 2010 operating at $70 \mathrm{eV}$ through a direct probe. Columns chromatography was carried out with silica gels (Aldrich $0.05-0.20 \mathrm{~mm}$ ). Silica gel F254G Vetec was used in preparing the TLC plates.

\section{Plant material}

The Stem Bark of A. Africanus was gotten from Federal Institute of Environment, Forestry Research Institute of Nigeria, in Ahiaeke, Umuahia, Abia State. It was identified by aTaxonomist at National Forestry Institute, Umuahia Nigeria. The stem bark of A. africanus was cleaned up and air dried at room temperature for a period of 2 weeks. After this, it was further grounded to powder.

\section{Extraction and isolation of the compound}

Reported methods of $[19,20]$ were used with slight modification. Nine hundred (900) g of the mashed stem bark were percolated with 3 litres of chloroform at room temperature for 48 hours (2 days), it was then filtered with Whatman filter paper No 1. The percolated stem bark was repercolated again with chloroform. The filtrate of the stem bark was concentrated by allowing it to stand at room temperature for 10 days while being covered with a perforated Whatman filter paper. It was allowed to evaporate to dryness till a sticky extract of a constant weight of $3 \mathrm{~g}$ was obtained. Column chromatography and ThinLayer Chromatography was carried out on the chloroformed crude extract in order to isolate, purify and characterise as well as identify its active constituents.

Two grams of the chloroform extract, was dissolved in $20 \mathrm{ml}$ chloroform. Sixty grams of silica gel were added to the mixture and stirred properly until slurry was formed. The slurry was continuously stirred until a dry homogeneous mixture was formed. The slurry was loaded on column and column chromatography was performed using standard procedure where solvents of different polarities like petroleum ether, chloroform and methanol were employed. The process of column chromatography lasted for 3 days, 25 fractions were collected and labelled. The flow rate was monitored.

In thin layer chromatography coated glass slide made of mixing silica gel in distilled water in the ration of 1:3 were used. The surface of the plate $(5.0 \mathrm{~cm}: 20 \mathrm{~cm})$ was wiped with clean cotton wool. The glass plate was coated carefully by smearing the surface with the slurry to form a thin layer plate. This was allowed to stand at room temperature for 3 hours before being activated for 1 hour in the oven for $100{ }^{\circ} \mathrm{C}$. The coated glass plates were now set for spotting. The process of spotting, developing and visualizing of the TLC was done using standard procedure. The retention factor (Rf) of each of the spots was determined using equation 1 .

$$
R f=\frac{\text { Dist. moved by spot }}{\text { Dist. moved by solvent }}(\text { Eqn } 1)
$$

This procedure involved using the coated plates as a stationary phase and the solvents of varying polarity as the mobile phase. For spotting, capillary tubes where used and TLC tanks for development. In cases where the visibility of the spot was not clear UV lamps and iodine tank was used to get a visible movement of the spot.

After rigorous TLC attempts no single spot was found, fractions that showed similar and positive spots where pooled together and finger column chromatography was carried out on them. Rf values of the fraction that gave a single spot were calculated. During finger chromatography, solvents of varying polarities like hexane, ethyl acetate, chloroform and methanol were used. 


\section{RESULTS AND DISCUSSION}

A single spot was obtained with $\mathrm{Rf}$ of 0.87 in a solvent mixture of hexane: chloroform, 2:8. The FT-IR spectrum of the isolated chloroformed stem bark extract of $A$. africanus is shown in Figure 2.

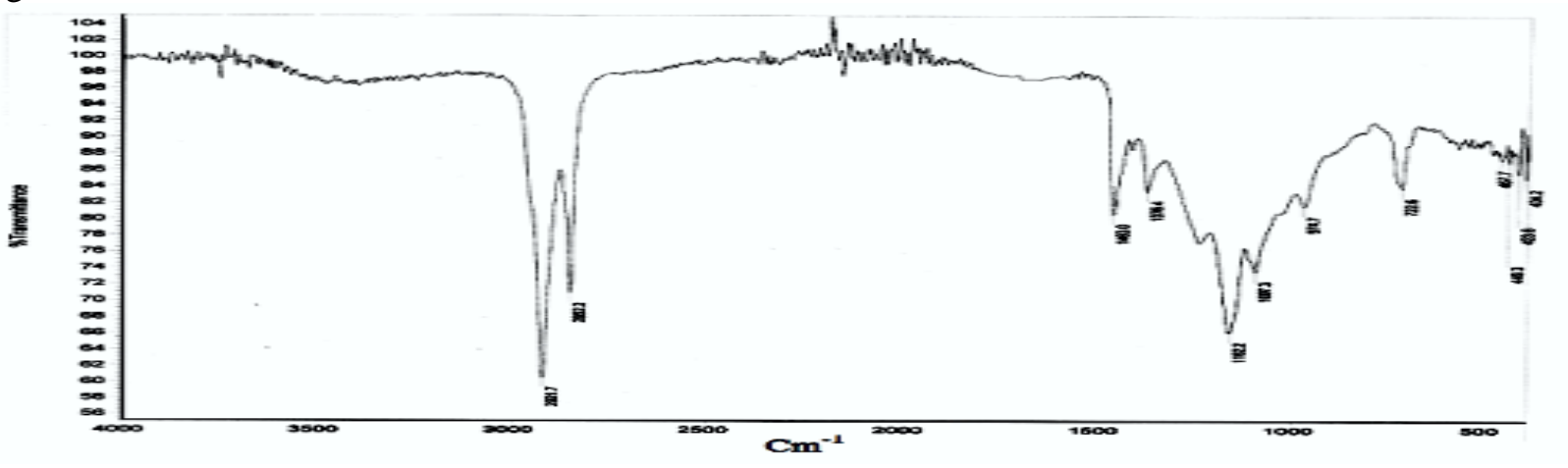

Figure 2: FT-IR spectrum of the isolated chloroformed stem bark extract of $A$. africanus

The IR spectrum shows vibrational frequencies at $2927.9 \mathrm{~cm}^{-1}$ and $2852.8 \mathrm{~cm}^{-1}$. These vibration frequencies where assigned to aliphatic $\mathrm{C}-\mathrm{H}$ stretch [21]. The peak at $1162.2 \mathrm{~cm}^{-1}$ is a typical peak for C-O stretch. The aromatic C-C stretch was observed at $1463 \mathrm{~cm}^{-1}$. The IR spectrum indicates that the compound is an aromatic derivative [22].

The Proton NMR of the isolated chloroformed stem bark extract of $A$. africanus is shown in Figure 3

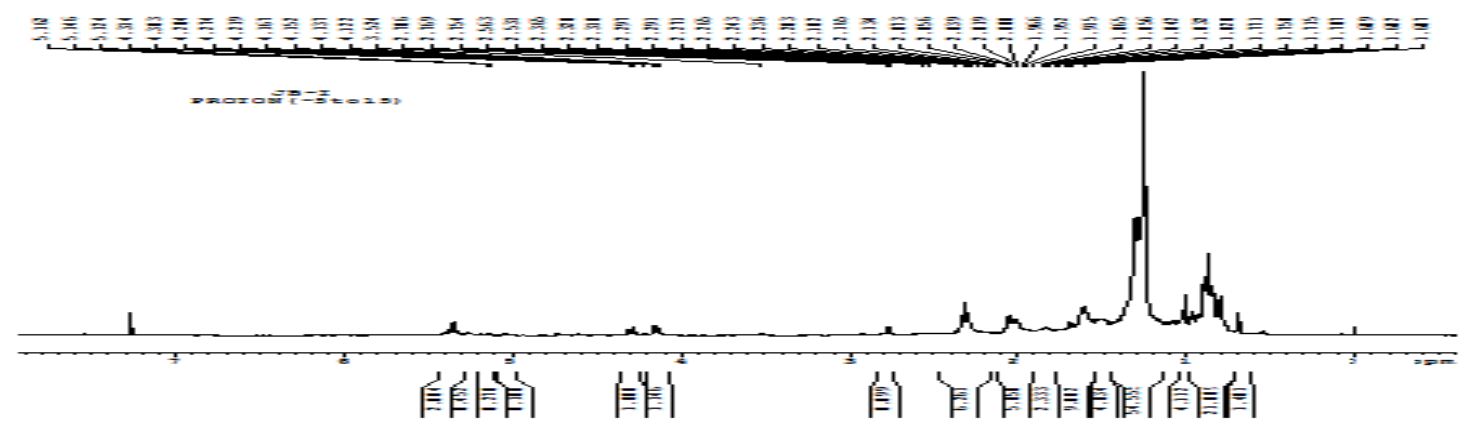

Figure 3: Proton NMR of the isolated chloroformed stem bark extract of A. africanus

The chemical shift value at $7.25 \mathrm{ppm}$ is a typical shift of aromatic protons [22]. This is in agreement with the infrared spectrum. The chemical shift values at 5.124, 5.146 and 5.162 ppm are the resonances for olefinic protons. They appeared as doublets of doublets of doublet [22]. Multiplets signals at 4.137, 4.167 and $4.314 \mathrm{ppm}$ corresponded to methyl proton attached to oxygen [22].

The H-H COSY of the isolated chloroformed stem bark extract of A. africanus is shown in Figure 4. 


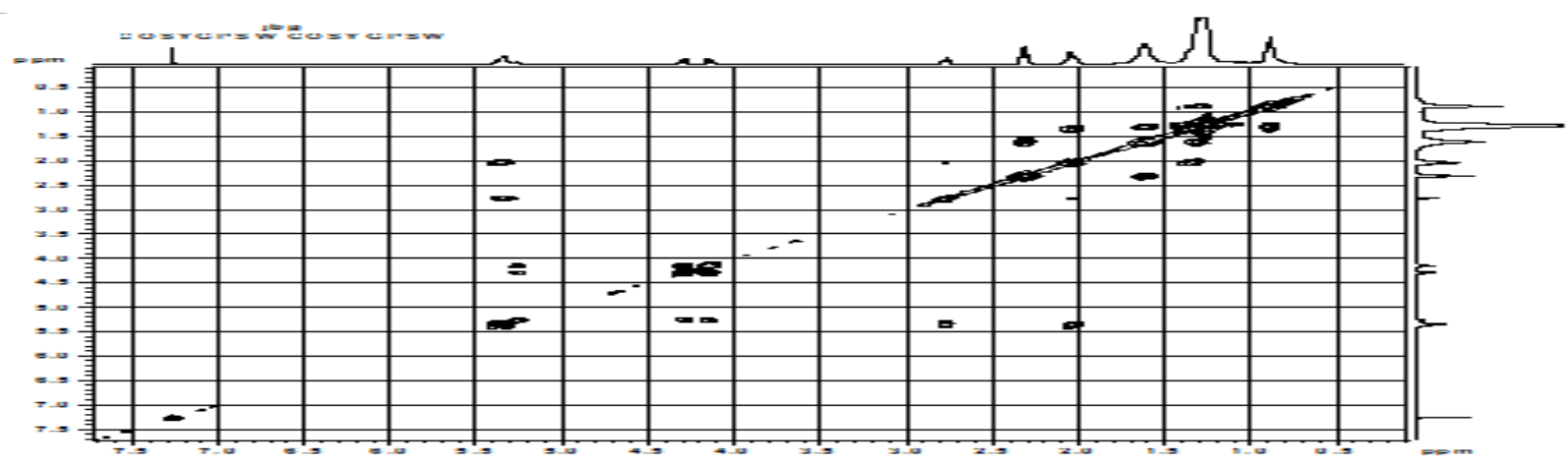

Figure 4: Proton-Proton COSY of the isolated chloroformed stem bark extract of A. africanus

The signal at $5.35 \mathrm{ppm}$ correlated with the signals at 2.786 and $2.008 \mathrm{ppm}$. The connectivity between these resonances suggested the presence of $-\mathrm{C}=\mathrm{C}-\mathrm{CH}_{2}-\mathrm{CH}_{2}-$ moiety. The signal at $5.162 \mathrm{ppm}$ correlated with the signal at 4.219 and $4.274 \mathrm{ppm}$. This connectivity between these resonances suggested the presence of $-\mathrm{C}=\mathrm{C}-\mathrm{O}-\mathrm{CH}_{2}-\mathrm{OCH}_{2}-$ moiety. The triplet signal at $2.75 \mathrm{ppm}$ correlated with the triplet signal at $2.05 \mathrm{ppm}$. The connectivity between the resonances suggested the presence of $-\mathrm{CH}_{2}-\mathrm{CH}_{2}$ - moiety. The triplet signal at $2.310 \mathrm{ppm}$ correlated with the signal at
$1.71 \mathrm{ppm}$. The connectivity between these

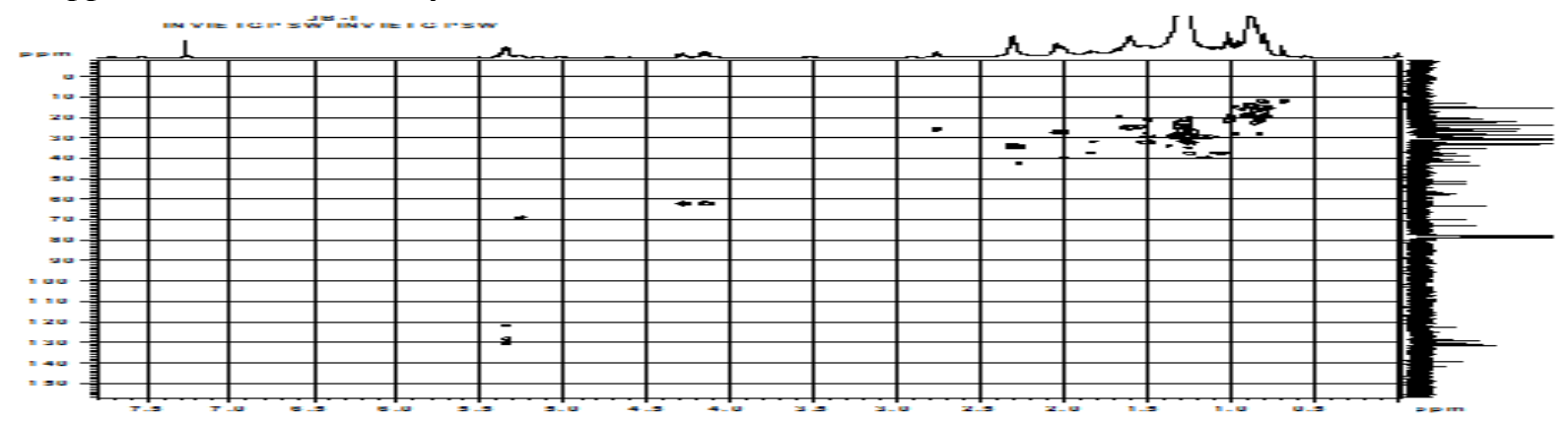

Figure 5: Proton-Carbon COSY NMR of the isolated chloroformed stem bark extract of A. africanus

The Proton signal at $5.35 \mathrm{ppm}$ correlated with the carbon chemical shifts at 130, 128 and 122 ppm. This shows that the proton is attached to a carbon that bears a double bond [22].This is in agreement with the suggested moiety in $-[-\mathrm{C}=\mathrm{C}$ ]- in H-H COSY. The proton signal at 5.126 ppm correlated with the carbon signal at $69 \mathrm{ppm}$. The connectivity suggested that the proton is attached to - C- O. This is also in agreement with the suggested moiety in the proton-proton resonances suggested the presence of $-\mathrm{CH}_{2}$ $\mathrm{CH}_{2^{-}}$moiety. Also, the triplets signal at $2.073 \mathrm{ppm}$ correlated with the signal at $1.3 \mathrm{ppm}$. This connectivity suggested a $-\mathrm{CH}_{2}-\mathrm{CH}-$ moiety. The singlet at $1.689 \mathrm{ppm}$ correlated with the doublet signal at $1.3 \mathrm{ppm}$. This connectivity suggested $-\mathrm{CH}-\mathrm{OH}$ moiety. The doublet signal at $1.3 \mathrm{ppm}$ correlated with the triplets at 0.895 $\mathrm{ppm}$. This correlation suggested the presence $\mathrm{CH}_{2}-\mathrm{CH}-$.

The C-H COSY of the isolated chloroformed stem bark extract of A. Africanus is shown in Figure 5
COSY. The multiplets signal in the proton at $4.274 \mathrm{ppm}$ correlates with the carbon signal at $62 \mathrm{ppm}$. This correlation indicated the presence of $-\mathrm{CH}_{2}-\mathrm{O}$ moiety. This is in agreement with the suggested moiety in the $\mathrm{H}-\mathrm{H}$ COSY. The proton multiplets signal at $4.219 \mathrm{ppm}$ correlated with the signal at $62 \mathrm{ppm}$. This also was in agreement with the suggested moiety in the proton-proton COSY. The multiplets in the ${ }^{1} \mathrm{H}-\mathrm{NMR}$ at 2.75 ppm correlated with ${ }^{13} \mathrm{C}$-NMR signal at 27.190 ppm. This connectivity between the resonances 
suggested aliphatic functionality, it has the presence of alkanes. This is also in agreement with the proton-proton COSY and FT-IR. The chemical shift values between $2.5 \mathrm{ppm}$ to 0.5 ppm in the proton NMR are all aliphatic $\left(\mathrm{CH}_{3} \mathrm{CH}_{2} \mathrm{CH}\right.$ protons) since they correlate with ${ }^{13} \mathrm{C}$ NMR chemical shift from 10 to $40 \mathrm{ppm}$.

The Carbon 13 DEPT is shown in Figures 6 and 7.

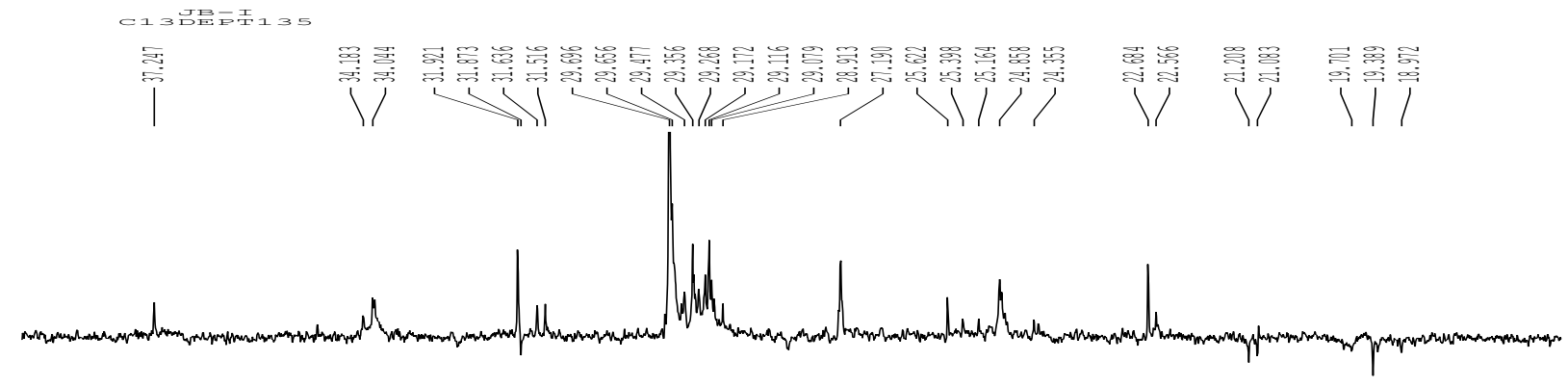

Figure 6: ${ }^{13} \mathrm{C}$-DEPT (135) NMR for the isolated chloroformed stem bark extract of A. africanus

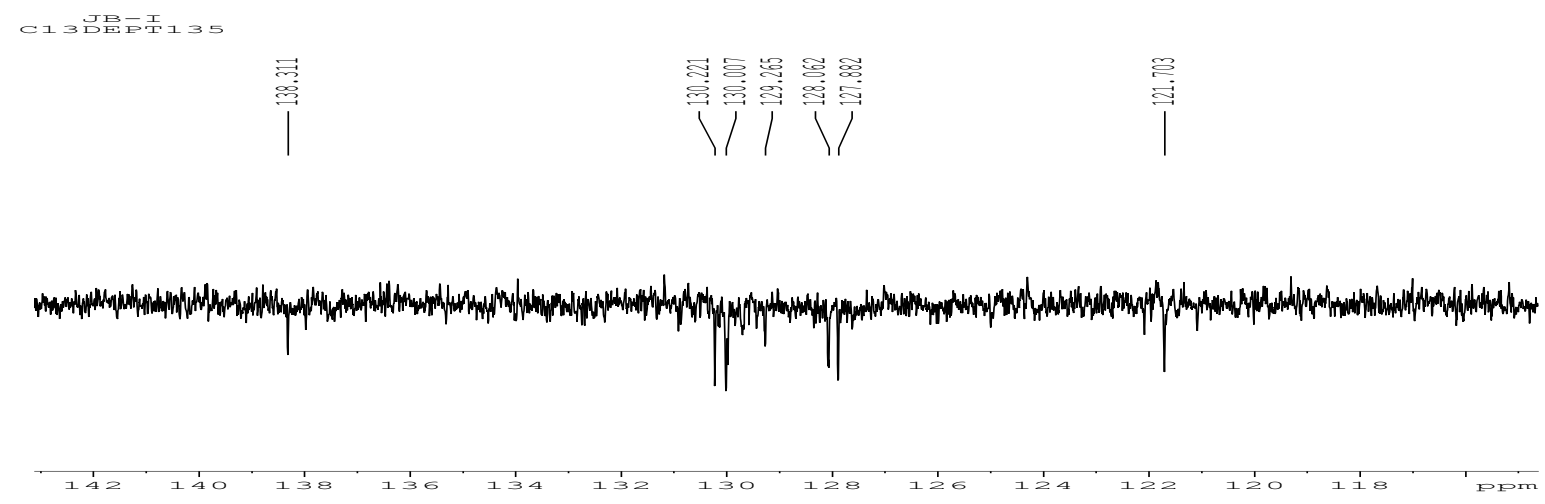

Figure 7: Expanded ${ }^{13}$ C-DEPT (135) NMR for the isolated chloroformed stem bark extract of A. africanus chemical shifts 121.703, 127.882, 128.062,

The $\mathrm{CH}_{3}$ and $\mathrm{CH}$ signals appear at the positive signals and the $\mathrm{CH}_{2}$ appeared at the negative signals. From Figure 6 the chemical shifts at 19.389, 21.083 and $31.921 \mathrm{ppm}$ are all $\mathrm{CH}_{2}$ signals. The remaining chemical shifts are all $\mathrm{CH}_{3}$ or $\mathrm{CH}$ signals. Figure 7 , which is the expanded ${ }^{13} \mathrm{C}$ NMR (135) DEPT shows the $129.265,130.007,130.221$ and $138.311 \mathrm{ppm}$ are all $\mathrm{CH}_{2}$ signals. 


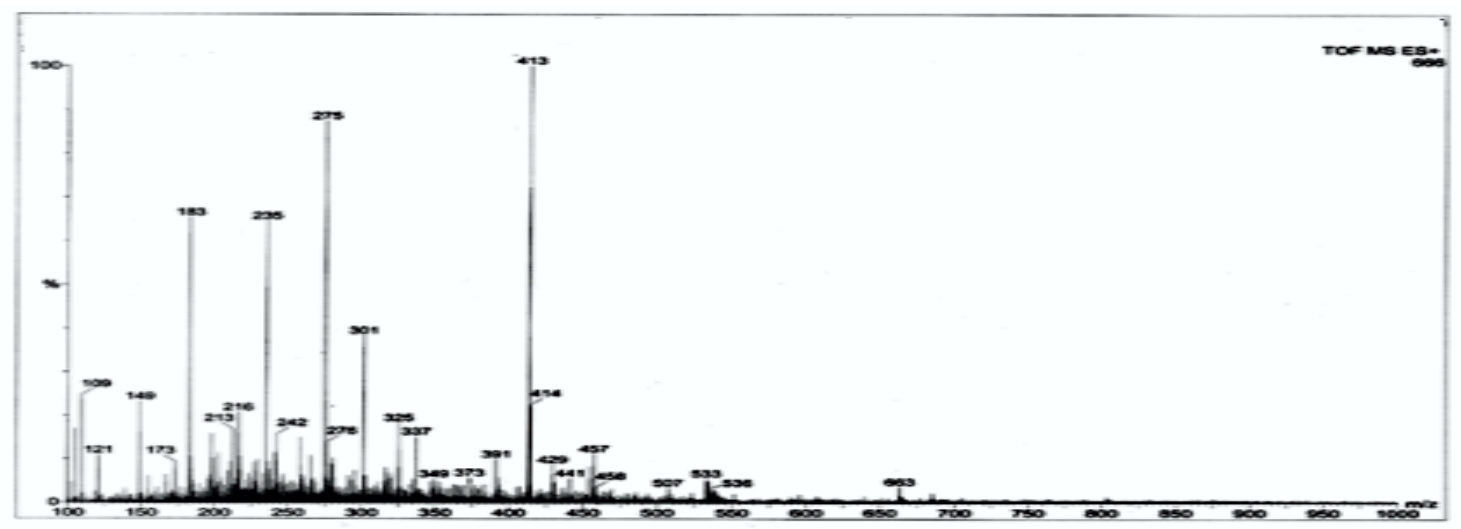

Figure 8: Mass Spectrum for the isolated chloroformed stem bark extract of A. africanus

The mass spectrum for the isolated chloroformed stem bark extract of A. africanus is shown in Figure 8. Mass spectroscopy is one of the spectroscopic tools used in the characterization of natural products [23-28]. The isolated compound showed a molecular ion peak at $\mathrm{m} / \mathrm{z} 663$. The peak at $\mathrm{m} / \mathrm{z} 663$ is the molecular ion. This represents the molecular weight of the isolated compound. The molecular formula of the isolated proposed structure is $\left[\mathrm{C}_{45} \mathrm{H}_{74} \mathrm{O}_{3}\right]^{+}$. This is a radical cation. The base peak - the peak with the highest intensity- appeared at $\mathrm{m} / \mathrm{z} 413$. This has a molecular formula $\left[\mathrm{C}_{28} \mathrm{H}_{45} \mathrm{O}_{2}\right]^{+}$. Fragmentation patterns of mass spectrum analysis are shown in Figure 9.1 and Figure 9.2. The fragments of $\mathrm{m} / \mathrm{z} 536$, corresponds with the molecular formula $\left[\mathrm{C}_{36} \mathrm{H}_{56} \mathrm{O}_{3}\right]^{+}$. The fragments at $\mathrm{m} / \mathrm{z} 533$ corresponded with molecular formula $\left[\mathrm{C}_{36} \mathrm{H}_{53} \mathrm{O}_{3}\right]^{+}$, this shows the loss of $3 \mathrm{H}$ atoms from the molecular ion. The fragments at $\mathrm{m} / \mathrm{z}$ 507 corresponded with the molecular formula $\left[\mathrm{C}_{34} \mathrm{H}_{51} \mathrm{O}_{3}\right]^{+}$. This has a total loss of $2 \mathrm{C}$ atoms and $2 \mathrm{H}$ atoms. The fragments at $\mathrm{m} / \mathrm{z} 458$ has a molecular formula $\left[\mathrm{C}_{30} \mathrm{H}_{50} \mathrm{O}_{3}\right]^{+}$.The other selected fragment with $\mathrm{m} / \mathrm{z} 457$ has a molecular formula $\left[\mathrm{C}_{30} \mathrm{H}_{49} \mathrm{O}_{3}\right]^{+}$with a total loss of $\mathrm{C}_{15} \mathrm{H}_{25}$ from the molecular ion. The fragment at $\mathrm{m} / \mathrm{z} 441$ has a molecular formula $\left[\mathrm{C}_{30} \mathrm{H}_{48} \mathrm{O}_{2}\right]^{+}$with a total loss of $\mathrm{C}_{15} \mathrm{H}_{26} \mathrm{O}$ from the molecular ion. The fragments at $\mathrm{m} / \mathrm{z} 429$ has a molecular formula $\mathrm{C}_{29} \mathrm{H}_{45} \mathrm{O}_{2}$ with a total loss of $\mathrm{C}_{16} \mathrm{H}_{29} \mathrm{O}$ from the molecular ion. 
J. Chem. Soc. Nigeria, Vol. 46, No.2, pp 0382 - 0392 [2021]

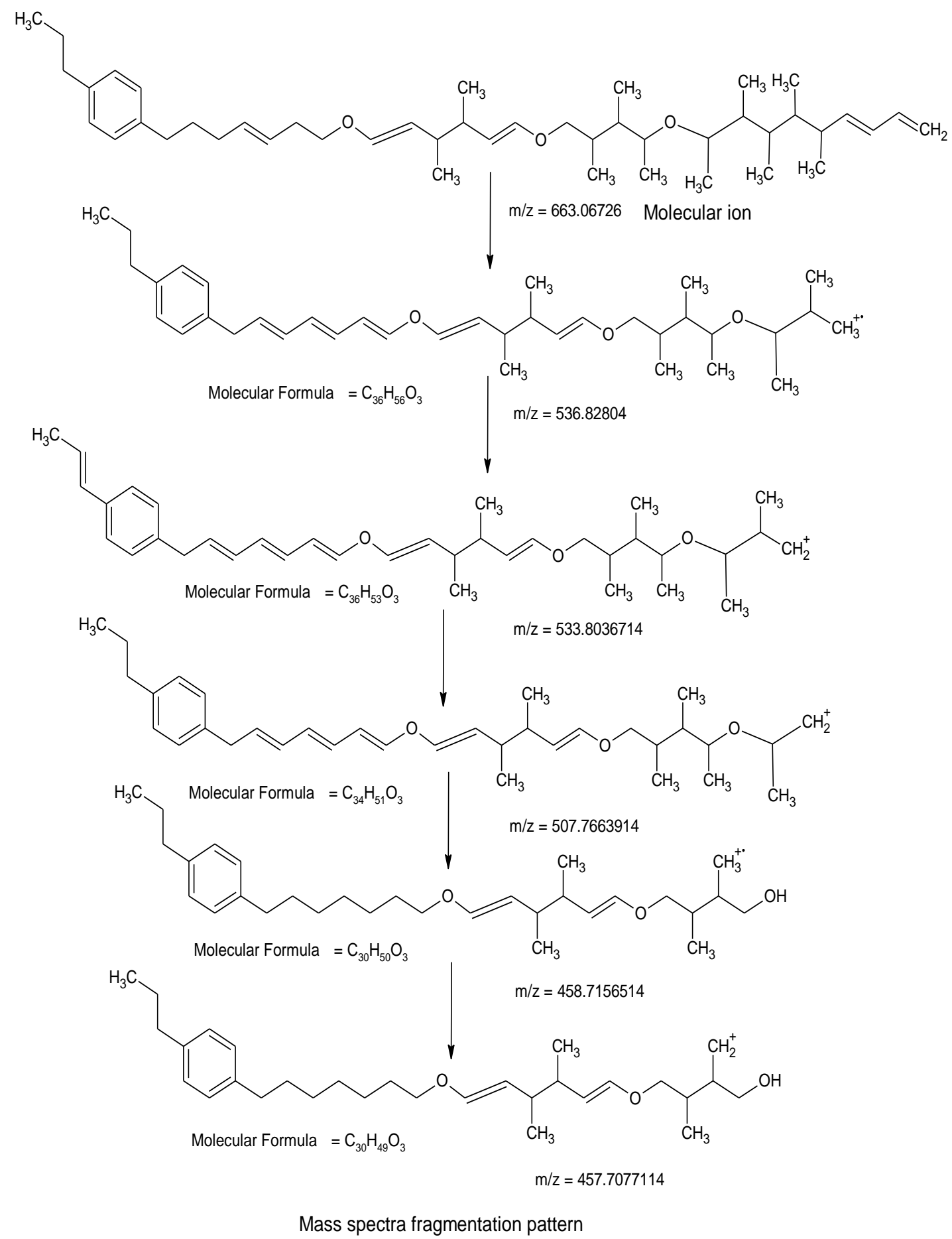

Figure 9.1: Suggested fragmentation pattern of the mass spectrum of the isolated chloroform stem bark extract of $A$. africanus 


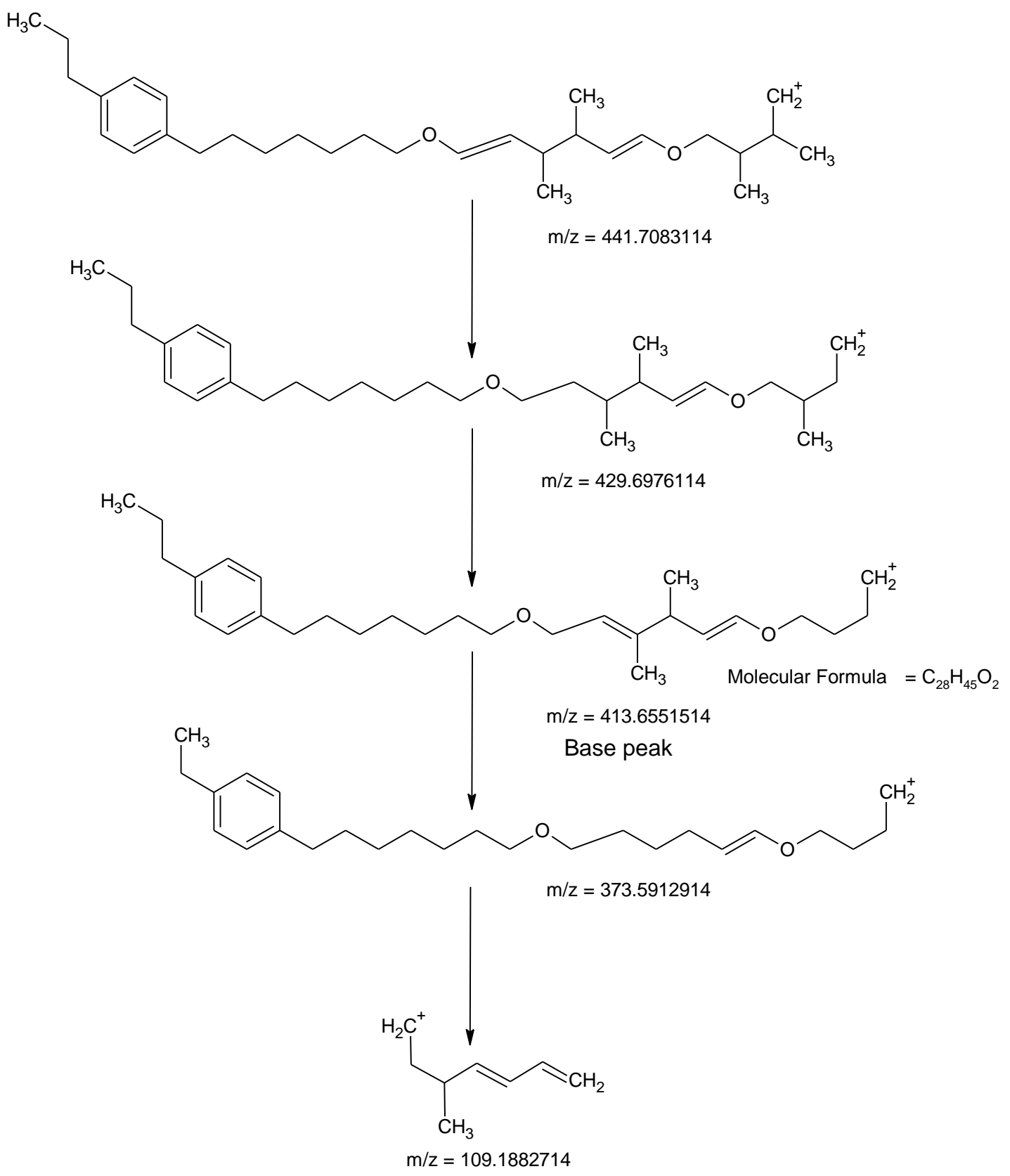

Mass spectra fragmentation pattern

Figure 9.2: Continuation of suggested fragmentation patterns of the mass spectrum of the isolated chloroformed stem bark extract of A. africanus

Based on the FT-IR, ${ }^{1} \mathrm{H}-\mathrm{NMR},{ }^{13} \mathrm{C}-\mathrm{NMR}, \mathrm{H}-\mathrm{H}$ the structure in Figure 10 have been proposed as COSY, H-C COSY, ${ }^{135}$ DEPT and mass spectra, the isolated chloroformed stem bark extract of $A$. africanus 


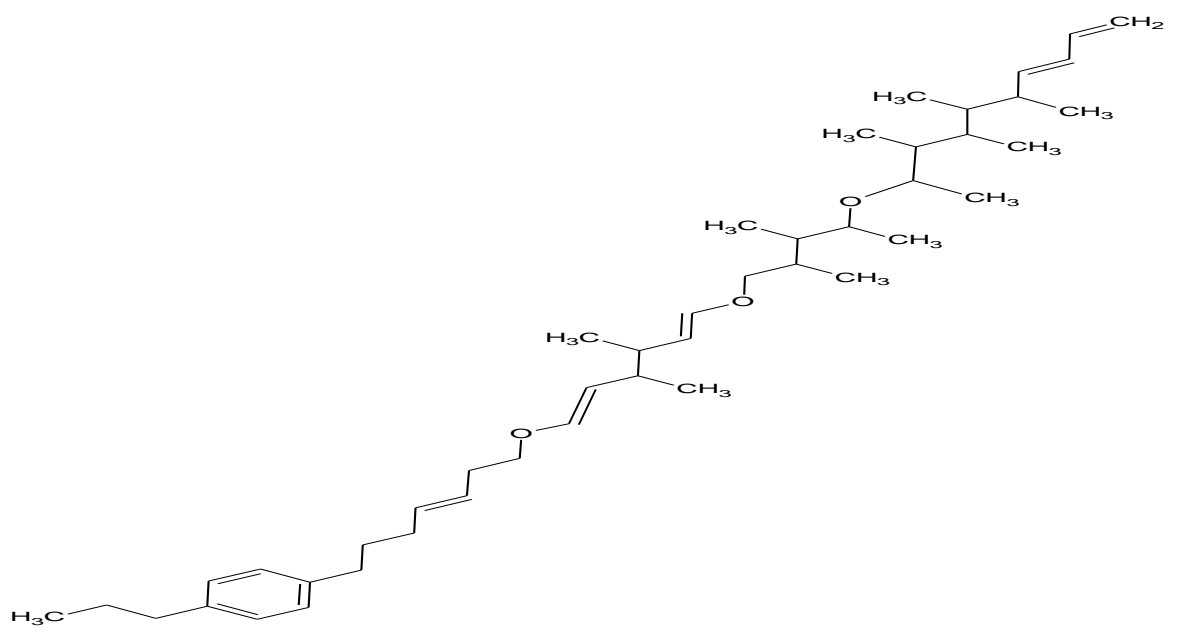

Figure 10: Proposed structure for the isolated chloroformed stem bark extract of A. africanus 1-((E)-7-(((1E,5E)-6-((2,3-dimethyl-4- $(((E)-3,4,5,6$-tetramethyldeca-7,9-dien-2yl)oxy)pentyl)oxy)-3,4-dimethylhexa-1,5-dien-1-yl)oxy)hept-4-en-1-yl)-4-propylbenzene

Allophylus natalensis and A. dreganus. Lipids, 40, 1051-1056.

\section{CONCLUSION}

1-((E)-7(((1E,5E)-6- $((2,3-$ dimethyl-4- $(((\mathrm{E})-$

3,4,5,6-tetramethyldeca-7,9-dien-2-

yl)oxy)pentyl)oxy)-3,4-dimethylhexa-1,5-dien1-yl)oxy)hept-4-en-1-yl)-4-propylbenzene is one the isolated compound from the chloroformed stem bark extract of $A$. africanus. This is the first time this compound is being isolated. The compound is aromatic and may contribute to the anti-inflammatory activities.

\section{REFERENCES}

[1] H.M. Burkill (1985). Useful plants of west tropical Africa. London: Royal Botanic Garden kew 181-182.

[2] M.O. Sofidiya, F.O. Jimoh, A.A. Aliero, A.J. Afolayan, O.A. Odukoya and B.O. Familoni (2012). Evaluation of antioxidant and antibacterial properties of six sapindaceae members. Journal of Medical Plants Research, 6(1), 154-160.

[3] I.A. Oladosu, S.O. Balogun and G.O. Ademowo (2013). Phytochemical screening, antimalarial and histopathological studies of Allophylus Africanus and Triagia benthamii. Chinese Journal Natural Medicine, 2013, 11(4), 371-376

[4] P. Avato, I. Rosito, P. Papadia and F.P. Fanizzi (2005). Cyanolipid-rich seed oils from
[5] M. Kumar, P. Rawat, D. Dixit, D. Mishra and A.K. Gautarn (2010). Anti- Ostereoporotic constituents from Indian medical plants.

Phytomedicine, 17, 993- 999.

[6] R. Hegnauer (1961).. Distribution of hydrocyanic acid in Cormophytes. New research on the distribution of Cyanogenesis. Pham. Week, b1, 96, 577-596.

[7] M. Díaz, A. González, L. Castro-Gamboa, D. Gonzalez and C. Rossini (2008). First record of 1-quebrachitol in Allophylus edulis

(Sapindaceae). Carbohydrate research, 343(15), 2699-2700.

[8] T.V. Rodriguez, J.V.Gonzales, L.M. Sanchez, M.N. Perez and E.M. Faz, (2005). Detection and determination of chemical groups in an extract of Allophylus Cominia (L). Journal of Herb Pharmacother. 5, 31-38.

[9] E.S. Priya, P.S. Selvan and R Tamilselvan (2012). Phytochemical investigation of Allophylus Serratus Kurz leaves by UV and GC-MS analysis. Research Journal of Phytochemistry 6, 17-24.

[10] I.A. Oladosu, S.O. Balogun and L Zhinqiang, (2014). Chemical composition and antioxidant potential of Essential oil from leaves and flowers of Allophylus Africanus. Journal of Essential oil-bearing plants, 13(5), 281- 287. 
[11] I.A. Oladosu, S.O. Balogun and L. Zhinqiang (2015). Chemical constituents of Allophylus Africanus. Chinese journal of Natural medicine, 13(2), 133- 141.

[12] A.K. Gupta and N Tandon (2004). Reviews on Indian medicinal plants, Indian Council of Medical Research, New Delhi, 2, 90 - 92

[13] A. Maurya and S.K. Srivastava (2010). Fast centrifugal partition chromatographic separation of abioactive nitrile glycoside "Niazirin" from the fruits of Moringa oleifera, The International Symposium on current status and opportunity in aromatic and medicinal plants (Aromed) CIMAP, Lucknow,

[14] V.S. Devi, M.G. Rao and M.U. Maheswari, (2014). Preliminary phytochemical screening of various extract of Valeriana wallichii root, Sky Journal of Biochemistry Research, 3(9), 80 85.

[15] T. Binu and A. Rajendran (2013). Less known ethnomedicinal plants used by Kurichar tribe of wayanard District, Southern western Ghats Kerala, Indian Botany Research International, 6(2), 32 - 35

[16] P.Dhramani and P.Gautam (2006). Exploring Indian medicinal plants for antiulcer activity, Indian Journal of Pharmacology, 38(2), $95-99$

[17] R.P. Rastogi and B.N. Mehrota (1995). Compendium of Indian medicinal plants, Publications \& Information Directorate, New Delhi, 4, 151

[18] K. Manmeet,R. Preeti, D. Preeti, M . Devendra, K. Abnish, R.P. Gautam, S. Divya, C. Naibedya and N. Rakesh, (2010). Antiosteoporotic constituents from Indian medicinal plants. Phytomedicine. 17, 993-999.

[19] E.O. JohnBull and C.B.C. Ikpa, Isolation, characterization and anti - cholinesterase activities of Physostigma venenosun (Calabar bean), American Journal of Scientific and Industrial Research, 4(2), 226 - 230 [20] E.O. JohnBull and S.O. Afolabi (2011). Bioactive evaluation of extracts of Euphorbia hirta:The antimicrobial and anticholinesterase approach, J. Phytomedicine and Therapeutics, 6(2), 79 - 84

[21] P.W. Hansen (1998). Urea determination in milk using Fourier Transform Infrared Spectroscopy and multivariate calibration. Milk Science International, 53, 251-255
[22] S.B. Mahoto, A.P. Kundu, A (1998). ${ }^{13}$ C NMR spectra of pentacyclic triterpenoids - A compilation and some salient features, Phytochemistry, 37 (6), 1517-1575.

[23] O.V. Ikpeazu, I.E. Otuokere, K.K. Igwe (2017). Preliminary Studies on the Secondary Metabolites of Buchholzia Coriacea (Wonderful Kola) Seed Ethanol Extract by GC-MS Analysis, Intern J Res Eng Appl., 7: 17-26

[24] I.E. Otuokere, F.J. Amaku, K.K. Igwe and G.C.Chinedum (2016). Medicinal studies on the phytochemical constituents of Judticia carnea by GC-MS analysis. American Journal of Food Science and Health, 2: 71-77

[25] I.E. Otuokere, D.O. Okorie, K.K. Igwe and U.I. Matthew (2016). Gas Chromatography-Mass Spectrometry Determination of Bioactive Phyto compounds in Chromolaena Odorata Leaf Extract, International Journal on Advances in Engineering Technology and Science, 2: $7-11$

[26] K.K. Igwe, A.J. Madubuike, C. Ikenga, I.E. Otuokere, and F.J. Amaku (2016). Studies of the medicinal plant Pausinystalia yohimbe ethanol leaf extract phytocomponents by GCMS analysis. International Journal of Scientific Research and Management. 4: 4116-4122

[27] K.K. Igwe, P.O. Nwankwo, I.E. Otuokere, S.N. Ijioma, F.J. Amaku (2015). GCMS analysis of phytocomponents in the methanolic extract of Moringa oleifera leave, Journal of Research in Pharmaceutical science, 20: 1-6

[28] U. Onyenze, I.E. Otuokere, J.C. Igwe (2016), Co (II) and Fe (II) mixed ligand complexes of Pefloxacin and Ascorbic acid: Synthesis, Characterization and Antibacterial Studies, Research Journal of Science and Technology, 8: 215-220 